\title{
The Readers' Division Chief
}

Mr. Jesse, librarian of the University of Tennessee, and Mr. Towne, librarian of Michigan State College, have collaborated in the portrayal of an administrative development which is claiming increased attention.

$\mathrm{T}$ HE RECENT APPOINTMENT of an assistant director for readers' services at Columbia University appears to have had the effect of crystallizing the thoughts of a considerable number of college and university librarians concerning the administrative answer to the old problem of a need for coordinating service to readers. Actually, the position is not a new one; the duties encompassed are the same as those already assigned to certain individuals in other institutions, and even the title has been used before. But the recognition of the problem at Columbia, and the announcement of the solution determined there, has given impetus to what had already assumed the aspect of at least an incipient trend.

When divisional forms of higher education were adopted at a number of institutions in recent years, one type of readers' division chief grew out of a recognition of the problems involved in attempting to serve semiautonomous divisional libraries having similarity in objectives rather than out of a recognition of the necessity for coordinating such form divisions as circulation, reference, departmental libraries, etc. In tracing the beginnings of the coordinating agency under discussion, proper recognition has to be given to such positions as the assistant in charge of branch libraries and the assistant in charge of total reference services.

At Columbia University it has now been felt that the units of the library system which serve the reader directly have a common purpose, and these are listed as the reference department, circulation departments, and "various special reading rooms - such as the periodical room, the browsing room, the lending service library, as well as the various college, school, and departmental libraries."

In a "Memorandum" issued over his signature on June 30, 1944, Director Carl M. White enumerated certain major duties for the new "assistant director: readers' services," which may be summarized as (I) duties in connection with collections, such as promoting a strong and rounded development of library resources, drawing upon bibliographic knowledge of the university staff, passing upon questions of duplication and acceptability and location of material, and passing upon such matters as storage and reader access; (2) duties in connection with services to readers, involving comparisons of departments, promotion of coordination and mutual understanding, interpretation of university policy, and compilation of records and other information; and (3) "line" duties, entailing linking the authority of the director and the heads of departments, gathering data regarding the library system as a whole, planning with assistants, approving recommendations for appointments, and exercising "veto power" on appointments within the division.

It is essential that the responsibilities, 
objectives, and authority of the readers' division chief be clear, and the further the definition extends beyond typical line administration, the better. Properly understood and properly executed, the position of readers' service chief can be the most effective device for accomplishing the ultimate in college and university library service: total understanding of, and accord with, all educational objectives, as ascertainable from the faculty both individually and collectively. The authors wish to stress at this point their conviction that much of the success which the venture may expect to attain will depend upon the clarity with which the broad aims and the detailed needs of the teaching faculty are understood and interpreted. The quest for this clarity will occupy much of our division chief's time and, conceivably, the majority of it during his first year of service. Actually, he need spend in the library proper only as much of his weekly schedule as is necessary to make his findings known to the staff and to be sure that he grasps the limits in personnel, physical plant, book resources, etc., so as not to place the library in that anomalous but recurring position of trying to catch up in service with what the public relations man has promised. The authors are not unaware of the difficulties to be encountered in trying to ascertain the objectives of the faculty or of the rarity of any situation which might be described as "total accord," but are convinced that one can at least come to grips with the problem, if it is approached with proper respect.

\section{Be Properly Accoutered}

Before the readers' division chief is sent out into the world to seek the golden fleece of "total accord," it is highly desirable that he be properly accoutered. One university librarian recently described the position in a prospectus: "For practical pur- poses the position should be such as to allow for entree about the campus and for executing without further authority all but major policy-forming duties in the assigned field. Salary and status will have to be fitted to the man, but in order to fit into the present library staff pattern, the position should carry the title of assistant librarian in charge of the readers' division and be accompanied by the appropriate faculty rank." The key word is "entree," and entree has social as well as academic and administrative prerequisites. Naturally, there will be no dragon-slaying even if the finest suit of armor in the land is buckled around a lightweight.

It was asserted earlier that the installation of a readers' division chief presented the aspect of a recent trend. This statement needs to be amplified and qualified. Harvard University has for a long time had an assistant librarian in charge of reference and circulation. The University of California defines the duties of the associate librarian as being responsible for the divisional agencies of loan and shelf, rental-reserve, reference, documents, and branch libraries. The Washington Square Library of New York University had a chief of the readers' department as early as 1926. Brown University developed this idea in connection with its subject-division form of library service adopted in 1939. The assistant librarian at the University of Nebraska was specifically in charge of the readers' division several years ago. The University of Illinois has appointed an assistant university librarian for public service departments. Recent conversations and correspondence with other college and university librarians show that the trend remains largely potential, however, by reason of the unavailability of qualified personnel.

The library schools are apparently already aware of the interesting possibilities 
in recruiting and training for this type of position but, of course, have been more or less helpless to do anything about it during the war. The authors are inclined to encourage a slight deviation from recruiting for library schools in the usual sense and to urge that it be attempted at a higher academic and professional level than has ordinarily been thought feasible. The potentialities of the position of assistant librarian in charge of readers' services have been discussed with a number of young instructors and assistant professors at various institutions, and a certain number of them could be brought into library work at a level which would constitute a promotion in rank and a better opportunity for the approach to higher education in its broadest sense. The status, duties, and salary should attract men of precisely the same caliber as those who are interested in such positions as assistant dean, assistant registrar, etc. If there ever was, or ever will be, a position in the library which is tailored to fit the young professor who is dissatisfied with overspecialization and who aspires to embrace the total educational program, it is that of the readers' division chief. The self-assigned recruiting officer is going to find it much easier to interest well-qualified candidates by being able to hold out the promise of something a little more appealing than the financial and educational sacrifices once proffered.

\section{Yeoman Service of G.L.S.}

The Graduate Library School has apparently done yeoman service in breaking down the idea that the university library can be an effective educational instrument as a one-man, one-professor, and onesalaried institution. The handful of young zealots who in the past decade have gone out from the institution which stands on Chicago's Midway have fought many battles and have lost many but have appar- ently so affected the thinking of the faculty and administrations of their respective universities that some of us are now finding it relatively easy to establish secondary and even tertiary administrative and professional positions of a nature to attract something more than mere martyrs.

An older and quieter school of thought has long surrounded the chair of librarianship with a certain aura of dignity and learning. With exceptions in a few very large research libraries, however, this type of thinking nonetheless too often resulted in the one-salary library, producing a situation which the authors feel can no longer make for satisfactory service.

There are undoubtedly those who will say that the functions of the position under discussion, as stated or implied, are no more than those which have been urged either by, or upon, head librarians for a long time. "Are not these functions and duties precisely those which the librarian himself should attempt to undertake?" The answer is yes, but in most medium-sized and large libraries the librarian has not undertaken them and he probably never will, because there has never been, and there probably never will be, time enough to escape from the innumerable outside contacts which he is expected to maintain. These are continual and may range all the way from chairing the program committee of a local luncheon club to going to China for a year or more.

The readers' service chief, therefore, becomes the right arm of the librarian, reaching into the campus to help solve a hundred problems which the librarian could never find time to attack. (A parallel case might be drawn up here for the librarian's left arm, that is, a chief of the technical processes, but, some opinion contrariwise, it is not felt that there must necessarily be such a parallel, even though it does look well on paper.) (See chart on page 320.) 
It is impractical in an article such as this to attempt to list in detail the duties of the readers' division chief, for they will vary greatly with each institution and will even fluctuate within an institution. Two illustrations are offered to show the type of project that can be undertaken by the readers' chief, which it would be impossible for the librarian of a large university to attempt. Except for the chance luncheon companion, the irate professor who carries his complaint all the way up, and a handful of close personal friends who form the habit of dropping in on the librarian, it is very difficult for the librarian to come to know individual faculty members well enough to get at their bibliographical problems. Whether or not he desires it, because of the demands upon his time, the librarian will gradually come to depend more and more upon university line administration and will end by dealing almost entirely with deans, directors, and department heads. The readers' division chief, if he is at all personally qualified for the position, will soon find that most of his lunches will be followed by thirty-minute extensions in the faculty club lounge, dealing with the specific book problems of some individual faculty member who may be, for example, simply a history instructor who has "been thinking for a long time" of the feasibility of a small office collection of certain specialized works to pass out informally to his confreres. This is, of course, a type of service which, in many instances, should not be refused by the library. Rarely indeed will there be found the university librarian who can spare thirty minutes after he has finished his lunch. That he should, is readily admitted; that he ordinarily does not, is inevitable.

Through the above approach, particularly to the lower academic ranks, it was learned by one recently appointed university librarian that, in a number of teaching departments on his campus, the book fund allotments were being hoarded for special subjects so undemocratically and so unsatisfactorily, by the heads of instruction, that many of the members of the faculty knew of no way to get a book ordered for the library. Yet library allotments to those departments were extremely liberal and in some cases actually generous! This is the sort of abuse which will come more promptly to the attention of the library administration if there is a readers' division chief.

\section{Assistant to Librarian Positions}

About ten years ago there appeared to be a trend toward the creation of the position of assistant to the librarian. This new

The projected organizational pattern which is being used for discussion at Michigan State College has the aspect of a balanced scale:

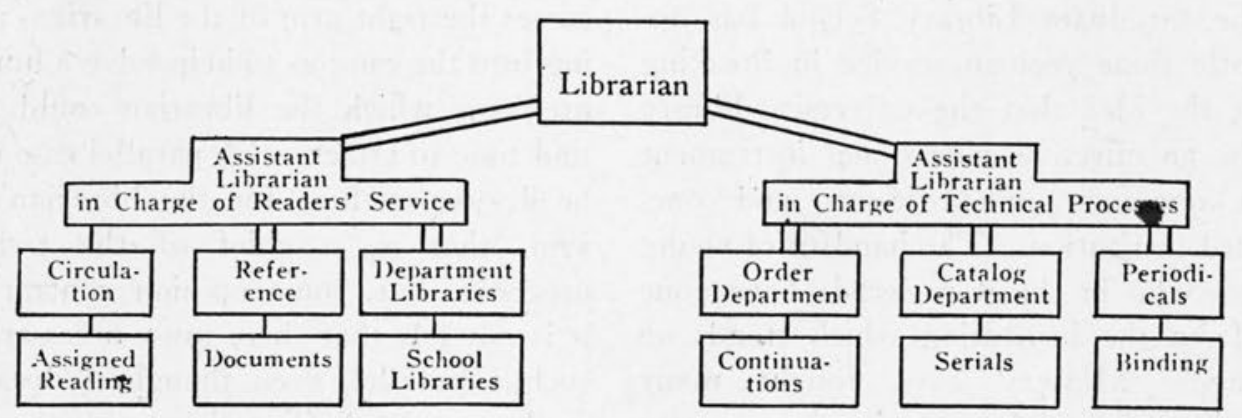


functionary was supposed to cure many of the librarian's headaches while occupying, from the library school's point of view, an especially attractive post-a post in which to place promising young men who, understandably, wanted to become librarians by short-cutting the generally accepted methods. In some cases this worked out, and is still working out, in a manner satisfactory to all concerned, but the idea has never progressed beyond the trend stage. It is possible that the number of actual appointments of readers' division chiefs may remain a mere trend and never reach the proportions of a movement.

However, the two positions are not analogous because of the potential markets. The most casual consideration of the placement possibilities for the post of assistant to the librarian shows the demand circumscribed by the number of very large libraries-the only ones that can afford to carry the extra cost of a relatively highsalaried staff member whose duties will be, at best, policy interpretation of a high degree. But in the case of the readers' division chief, the potential market may be said to include every college and university library where it is recognized that a close relationship between the faculty and staff is desirable and is worth paying for and where it is also recognized that the librarian himself cannot find time to act as a complete liaison officer.

Small libraries should and will depend upon the librarian and the department heads. Some of the larger libraries will want to employ a sort of supercirculation chief or superreference chief. In such cases the supercirculation or superreference chief will, in many instances, be a readers' services chief with merely another title. Except as one of the already heavily stressed accouterments for entree, the actual title of assistant librarian in charge of readers' services is not advocated here because of any inherent magical quality in the combination of words.

Other and better solutions will undoubtedly present themselves or be discovered later for a proper medium of readers' service coordination and library-faculty cooperation, but for the time being, in college and university libraries, the authors suggest unification of readers' service under a readers' division chief.

\section{Something New in Cataloging}

\section{(Continued from page 296)}

doing the many things a catalog department always wants to do but for which it never has the time.

If several drives of a week's duration are planned, the bulk of the work for the year will be compressed into about two months. This should mean that during the remainder of the year the cataloger will not be under pressure and will be free to work on a number of matters which normally have to be set to one side waiting for a better day which never seems to come. This will provide a variety and interest in the cataloger's program which is now often lacking. 